\title{
Postpartum Depression Among Women With Previous Infertility in Health Care Centers of Hamadan in 2018
}

\author{
Nasrin Matinnia ${ }^{(\mathbb{D}}$, Saeid Yazdi-Ravandi ${ }^{2,3^{*}}$ \\ 'Department of Nursing, College of Basic Science, Hamedan Branch, Islamic Azad University, Hamedan, Iran \\ ${ }^{2}$ Behavioral Disorders and Substance Abuse Research Center, Hamadan University of Medical Sciences, Hamadan, Iran \\ ${ }^{3}$ Young Researchers and Elite Club, Roudehen Branch, Islamic Azad University, Roudehen, Iran
}

\begin{abstract}
Background: Childbirth is one of the essential goals of the family, so that infertility can cause many problems for the family. Therefore, the aims of the current study were the frequency of postpartum depression and evaluate the relationship between postpartum depression, socio-demographic factors, and quality of marital satisfaction in postpartum women with a history of infertility referring to health centers in Hamadan.

Methods: This study was a cross-sectional study. The study population consisted of all primiparous women with a history of infertility referring to Hamadan health care centers in 2018, of which 240 randomly selected according to the inclusion criteria for one year. Subjects assessed by demographic and clinical information checklist, Edinburgh Postnatal Depression Scale (EPDS), and marital relationship quality scale (Revised Dyadic Adjustment Scale; RDAS). All statistical calculations performed by busing chi-square with SPSS- 17 .

Results: 152 out of 240 participants (63.3\%) had a degree of depression, of which $57(23.7 \%)$ had mild depression, $63(26.3 \%)$ had moderate depression, and $32(13.3 \%)$ had severe depression. According to the result of the study, marital satisfaction in $23.3 \%$ (56), 37.1\% (89), and $39.6 \%$ (95) were excellent, moderate, and low, respectively - the quality of marital relationships associated significantly with and postpartum depression $\left(\chi^{2}=19.3, P<0.001\right)$. The results of the study showed that there was a significant relationship between age, occupation, educational level, duration of infertility, and depression $(P<0.05)$, but there was no significant relationship between ethnicity, insurance, and depression $(P<0.05)$.

Conclusion: Regarding the results obtained in this study and comparison with existing studies, the infertility problem can cause mental and psychological disorders in women. It seems that marital satisfaction and its relationship with different factors and the proper interventions by health care providers are necessary to prevent postpartum depression in these women.

Keywords: Depression; Postpartum; Marital satisfaction; Infertility.
\end{abstract}

*Correspondence to Saeid Yazdi-Ravandi, Ph.D. Behavioral Disorders and Substance Abuse Research Center, Hamadan University of Medical Sciences, Hamadan, Iran Tel: +98-08138271066 Email: Saeid_yazdiravandi@ yahoo.com

Published online March 10, 2020

Citation: Matinnia N, Yazdi-Ravandi S.Postpartum Depression Among Women With Previous Infertility in Health Care Centers of Hamadan in 2018. Int Clin Neurosci J. 2020;7(2):103-108. doi:10.34172/icnj.2020.08.

\section{Introduction}

Childbirth is one of the essential goals of the family, so that infertility can cause many problems for the family. ${ }^{1}$ Infertility often described as a crisis or problem in the family, which can be an obstacle to achieving parental social roles and lead to emotional, physical, and financial problems. ${ }^{2}$ Just about one of seven couples experience infertility after one year of unprotected sex. ${ }^{3}$ Historically, this is an exclusively related concern for women, which may cause adverse interactions between the mother and the child, adversely affect the child's development and, in severe cases, cause child abuse. ${ }^{4}$ People with a history of infertility usually experience feelings of shame, sin, depression, and anxiety. ${ }^{5}$ Pregnancy and childbirth can reduce these emotions because of the link between mother and infant in processes such as baby care and breastfeeding. ${ }^{6}$ Infertility creates many psychological consequences for couples, which can be considered as one of the unpleasant experiences in their life and make it a psycho-social crisis for them. These people may interpret infertility problems as indications that they have no "ability" or "value" of parenting. ${ }^{7}$ Researches have shown that men and women often face different ways to cope with unpredictable infertility, which can increase divorce

(C) 2020 The Author(s). This is an open access article distributed under the terms of the Creative Commons Attribution License (http:// creativecommons.org/licenses/by/4.0/), which permits unrestricted use, distribution, and reproduction in any medium, provided the original work is properly cited. 
and distance in marital relationships. Unfortunately, when their peers and relatives become pregnant, these couples are often more likely to be separated from their relatives and friends. ${ }^{8}$ Stress in infertile couples disrupts marital satisfaction, reduces self-esteem, and the number of couples' sexual relationships. The set of these feelings leads to depression, anxiety, the feeling of disability, and sin in them. While couples are in the process of treatment for fertility, the purpose of sexual activity is just pregnancy. Moreover, it could increase marital conflicts and a lack of enjoyment of life. ${ }^{9}$

Women are often disappointed with infertility treatment and may be upset by the lack of understanding of their spouse. ${ }^{10}$ In addition to experiencing the psychological problems caused by infertility, infertile couples encounter physical and financial stress if they decide to use fertility assisted methods, which can affect their marital quality. ${ }^{4}$ Therefore, a combination of physical, psychological, and economic stress associated with social isolation often increases the pressure on marital relationships in infertile couples. ${ }^{2}$ After treating infertility, couples may be anxious, particularly about the pregnancy and the health of the baby after birth, which increases the chance of postpartum depression. ${ }^{11}$ Although depression is one of the most common diseases in modern societies, referral to help receive much less than its actual outbreak. ${ }^{12}$ According to the Diagnostic and Statistical Manual of Psychiatric Disorders of the American Psychiatric Association, Postpartum Depression (PPD) defined as an episode of severe depression occurring during the first four months after delivery. ${ }^{13}$ The psychological and emotional effects of infertility may not easily diagnose, and many couples prefer to remain quiet about this problem. ${ }^{14}$ The prevalence of postpartum depression in the new mothers is about $13 \% .{ }^{15}$ It is essential to differentiate PPD from postpartum blues, which experienced in most women (at least 70\%) in the first ten days after childbirth. ${ }^{13}$ Postpartum depression is debilitating and prolonged disorder, and in addition to symptoms of depression (such as depressed mood, lack of pleasure from something, sleepiness, changes in sleep patterns or eating, feeling unworthy or frustrated). It is commonly associated with worries about child health. ${ }^{13}$ The results of existing studies on the impact of infertility on psychiatric problems have been different, and the psychological effects of previous infertility have not thoroughly investigated. There are also controversial results on the prevalence of postpartum depression in couples, who have been successful in infertile treatment, and most studies in couples are infertile, not couples who have been treated infertility. Given the above inconsistencies and the high prevalence of infertility in the society, Hence, more research is required to adequately study the factors that impact postpartum depression in infertile women. Therefore, the aims of the current study were the frequency of postpartum depression and evaluate the relationship between postpartum depression, sociodemographic factors, and quality of marital satisfaction in postpartum women with a history of infertility referring to health centers in Hamadan.

\section{Materials and Methods}

This study was a cross-sectional study. The study population consisted of all primiparous women with a history of infertility referring to Hamadan health care centers in 2018, of which 240 randomly selected according to the inclusion criteria for one year. The sampling method in this study was multi-stage. A list of all health care centers in Hamadan used as a sampling frame in the first stage. Eight health centers randomly selected in the second stage. In the third stage, all primigravida women provided with their files number in each health center. The eligible women were selected based on the inclusion and exclusion criteria invited to participate in this study. This study designed to uphold the ethical protection of participants. All participants have given explanations of the research aims, as well as assured that the information would be confidential. Before enrolling in the study, each participant required to provide informed consent, through which they indicated that they understood $(a)$ what expected of them and $(b)$ that they were under no obligation to participate in or complete this questionnaire. The inclusion criteria include having at least elementary schooling, residing in Hamadan, having a history of infertility, and refer to health care centers during four weeks after delivery (p. 186 DSM5) for self-care or neonate, and the successful outcome of delivery with the healthy new-born. Exclusion criteria include the history of medical illness with severe complications during pregnancy, history of taking antidepressants, psychiatric disorders, systemic illness (which causes symptoms of depression), and dependency on cigarettes, alcohol, and drugs. Subjects assessed by demographic and clinical information checklist, Edinburgh Postnatal Depression Scale (EPDS), and marital relationship quality scale (Revised Dyadic Adjustment Scale; RDAS). All statistical calculations were performed using SPSS software version 17 and taking into account the significance level of 0.05 . Descriptive statistics, including frequency and mean, and inferential level investigated by using chi-square.

\section{Demographic and Clinical Information Checklist}

These included characteristics such as age, education, and obstetrics history, the cause of infertility, the duration of infertility, and the method of childbirth.

\section{Edinburgh Postnatal Depression Scale}

The instrument of this study was the EPDS. This questionnaire has ten items and designed to detect depression during six weeks of postpartum. The score for the Edinburgh scale is between 0 and 30, and score 
12 or more considered as postpartum depression. The questions number $1,2,3,4,5$, and 6 from 3 to 0 , and 7,8 , 9,10 from 3 to 0 scored. The validity of this questionnaire has evaluated in several countries, and its reliability was confirmed by Cox et al that Cronbach's alpha was $0.88 .{ }^{16} \mathrm{~A}$ study by Montazeri et al in Iran on 100 women postpartum depression was determined, and the reliability of this questionnaire has also assessed. The Cronbach's alpha coefficient in 6-8 weeks and 12-14 days after delivery was 0.77 and 0.86 , respectively. ${ }^{17}$ In the present study, Cronbach's alpha coefficient for the Edinburgh questionnaire was 0.75 . In this study, the score of 13 and above considered as postpartum depression. Accordingly, mothers were referred to the psychiatrist to confirm their depression and more effective measures.

\section{Marital Relationships Quality Scale (RDAS)}

This scale was designed and constructed by Busby et al in 1995, which measures the quality of the marital satisfaction relationship in three subscales of mutual agreement, mutual consent, and mutual cohesion. ${ }^{17,18}$ It has 14 questions rated on a 6-point Likert scale (0-5), with the answer fully agreeing to the RDAS score of 5 and opposite to zero. High scores indicate higher marital quality, and lower scores indicate unfavorable marital relationships. In Iran, the internal validity of this questionnaire has obtained using Cronbach's alpha between 0.90- 0.70, and its reliability in the study of Iranian nulliparous pregnant women was $0.84 .{ }^{19}$

\section{Results}

In this study, the mean age of participants was 36 years, with a minimum age of 20 and a maximum of 48 years. Out of 240 samples, 53\% were in the age group of 44-35 years old. Most of the participants had a diploma and housewives. The maximum duration of marriage was 2 to 5 years; the duration of infertility was $63 \%$ less than five years, $28 \%$ between $5-10$ years, and $9 \%$ more than ten years (Table 1).

The results of the study showed that there was a significant relationship between age, occupation, educational level, duration of infertility, and depression $(P<0.05)$, but there was no significant relationship between ethnicity, insurance, and depression $(P<0.05)$. As shown in Table 2, depression was higher in people aged between 25-34 who had a high school diploma, as well as depression more was observed in those who had specialized occupations and whose duration of marriage was between $5-10$ years $(P<0.01)$

The mean score and standard deviation of EPDS were in women with a history of infertility $(84.7 \pm 33.79)$. Totally 152 out of 240 participants $(63.3 \%)$ had a degree of depression, of which 57 (23.7\%) had mild depression, $63(26.3 \%)$ had moderate depression, and 32 (13.3\%) had severe depression. The mean and standard deviation of marital satisfaction was $50.48 \pm 15.4$. According to the result of the study, marital satisfaction in $23.3 \%$ (56), $37.1 \%$ (89), and 39.6\% (95) were excellent, moderate, and low, respectively. The quality of marital relationships associated significantly with and postpartum depression; $\left(\chi^{2}=19.3, \mathrm{P}<0.001\right)$ (Table 3$)$.

\section{Discussion}

The aims of the current study were the frequency of postpartum depression and evaluated the relationship between postpartum depression socio-demographic factors in postpartum women with a history of infertility referring to health centers in Hamadan. In the present study, $63.3 \%$ of mothers have reported some degree of depression. Infertility has considered a personal crisis that can cause stress and psychological pressure on couples and, in various ways, threaten their mental health. It can also impair marital quality, reduce intimacy and fear of

Table 1. Demographic characteristics of participants in the study

\begin{tabular}{|c|c|}
\hline Socio-demographic & No. $(\%)$ \\
\hline \multicolumn{2}{|l|}{ Age } \\
\hline $20-24$ & $12(5)$ \\
\hline $25-34$ & $84(35)$ \\
\hline $35-44$ & $127(53)$ \\
\hline$\geq 45$ & $17(7)$ \\
\hline \multicolumn{2}{|l|}{ Ethnicity } \\
\hline Fars & $179(74.6)$ \\
\hline Kurd & $20(8.3)$ \\
\hline Lor & $16(6.7)$ \\
\hline Turk & $25(10.4)$ \\
\hline \multicolumn{2}{|l|}{ Education } \\
\hline Primary school & $17(7.1)$ \\
\hline Secondary school & $49(20.4)$ \\
\hline High school diploma & $120(50)$ \\
\hline Bachelor degree or higher & $54(22.5)$ \\
\hline \multicolumn{2}{|l|}{ Occupation } \\
\hline Non-professional employee & $76(31.7)$ \\
\hline Professional employee & $47(19.6)$ \\
\hline Self-employed & $30(12.5)$ \\
\hline Housewife & $87(36.2)$ \\
\hline \multicolumn{2}{|l|}{ Insurance } \\
\hline Yes & $182(75.8)$ \\
\hline No & $58(24.2)$ \\
\hline \multicolumn{2}{|l|}{ Duration of marriage } \\
\hline Less than 2 years & $22(9.2)$ \\
\hline 2 to 5 years & $72(31.2)$ \\
\hline 5 to 10 year & 109 (44.6) \\
\hline More than 10 years & $37(16)$ \\
\hline
\end{tabular}


Table 2. Relationship Between Demographic Variables and Depression

\begin{tabular}{|c|c|c|c|}
\hline \multirow[b]{2}{*}{$\begin{array}{l}\text { Depression } \\
\text { Socio-demographic }\end{array}$} & \multicolumn{2}{|c|}{ Postpartum } & \multirow[b]{2}{*}{$P$ Value } \\
\hline & $\begin{array}{l}\text { No Depression } \\
\text { No. }(\%) \\
(\mathbf{n}=\mathbf{8 8})\end{array}$ & $\begin{array}{c}\text { Depression } \\
\text { No. }(\%) \\
(n=152)\end{array}$ & \\
\hline \multicolumn{4}{|l|}{ Age } \\
\hline $18-24$ & & $21(23.9)$ & \multirow{4}{*}{$0.02^{*}$} \\
\hline $25-34$ & $34(38.6)$ & $65(42.8)$ & \\
\hline $35-44$ & $28(31.8)$ & $43(28.2)$ & \\
\hline$>45$ & $5(5.7)$ & $7(4.7)$ & \\
\hline \multicolumn{4}{|l|}{ Ethnicity } \\
\hline Fars & $20(22.7)$ & $43(28.3)$ & \multirow{4}{*}{$>0.05$} \\
\hline Kurd & $23(26.1)$ & $34(22.4)$ & \\
\hline Lor & $24(27.3)$ & $36(23.7)$ & \\
\hline Turk & $21(23.9)$ & $39(25.6)$ & \\
\hline \multicolumn{4}{|l|}{ Education } \\
\hline Primary School & $21(23.9)$ & $19(12.5)$ & \multirow{4}{*}{$0.01^{*}$} \\
\hline Secondary School & $32(36.4)$ & $51(33.6)$ & \\
\hline High School Diploma & $18(20.4)$ & $43(28.3)$ & \\
\hline Bachelor Degree or Higher & $17(19.3)$ & $39(25.6)$ & \\
\hline \multicolumn{4}{|l|}{ Occupation } \\
\hline Non Professional Employee & $16(18.2)$ & $17(11.2)$ & \multirow{4}{*}{$0.03^{*}$} \\
\hline Professional Employee & $25(28.4)$ & $75(49.3)$ & \\
\hline Self-Employed & $10(11.4)$ & $12(7.9)$ & \\
\hline Housewife & $36(40.9)$ & $48(31.6)$ & \\
\hline \multicolumn{4}{|l|}{ Insurance } \\
\hline Yes & $76(86.4)$ & $128(84.2)$ & \multirow[t]{2}{*}{$>0.05$} \\
\hline No & $12(13.6)$ & $24(15.8)$ & \\
\hline \multicolumn{4}{|l|}{ Duration of marriage } \\
\hline Less than two years & $6(6.8)$ & $15(9.9)$ & \multirow{4}{*}{$0.01^{*}$} \\
\hline 2 to 5 years & $21(23.9)$ & $52(34.2)$ & \\
\hline 5 to 10 year & $45(51.1)$ & $57(37.5)$ & \\
\hline More than ten years & $16(18.2)$ & $28(18.4)$ & \\
\hline
\end{tabular}

termination of relationship, separation, and divorce, reduce self-esteem and feelings of rejection from the family and the community that the set of these factors can predispose a person to the psychological disorders such as postpartum depression and a weakening in marital quality. Postpartum depression is one of the most critical problems that threaten the health of the mother, infant, and family. Studies reported that the prevalence of severe postpartum depression with clinical symptoms is between $10 \%-20 \%{ }^{20,21}$ It seems that one of the reasons for the difference in reported prevalence in various articles is that the different times of study after childbirth. For example, some researchers have examined depression during the first two weeks after delivery, which may include postpartum blues. Some of them have studied PPD a long time after childbirth, which results in the disappearing of this disorder. ${ }^{22}$ In the current study, all the cases evaluated within 4-6 weeks after birth that the symptoms of postpartum blues, which are very similar to postpartum depression, disappeared. On the other hand, some researchers have studied primigravida and multiparous women together. However, in the present study, only the primigravida was assessed, and the factors that may be related to postpartum depression in primiparous women such as the history of depression before pregnancy, during pregnancy, prenatal and disorders related to pregnancy were excluded.

The results of this study showed that there is a significant relationship between age, occupation, education level, duration of the marriage, duration of infertility, and their depression $(P<0.01)$. Other findings also show that there is a significant relationship between 
Table 3. Relationship Between the Quality of the Marital Relationship and Postpartum Depression

\begin{tabular}{|c|c|c|c|c|c|}
\hline \multirow[b]{2}{*}{$\begin{array}{l}\text { Quality of Marital } \\
\text { Relationship }\end{array}$} & \multicolumn{3}{|c|}{ Postpartum Depression } & \multirow[b]{2}{*}{$x^{2}$} & \multirow[b]{2}{*}{$P$ Value } \\
\hline & $\begin{array}{c}\text { No \& Mild Depression } \\
\text { No. }(\%)\end{array}$ & $\begin{array}{c}\text { Moderate Depression } \\
\text { No. }(\%)\end{array}$ & $\begin{array}{c}\text { Severe } \\
\text { Depression } \\
\text { No. }(\%)\end{array}$ & & \\
\hline Low & $41(43.2)$ & $34(35.8)$ & $20(21)$ & & \\
\hline Moderate & $48(53.9)$ & $25(28.1)$ & $16(18)$ & 19.3 & $<0.001$ \\
\hline Good & $37(66.1)$ & $12(21.4)$ & 7 (12.5) & & \\
\hline
\end{tabular}

maternal age and postpartum depression, which is consistent with these results. ${ }^{23,24}$ For example, maternal age in Rahmani's research is one of the practical factors in postpartum depression. ${ }^{23}$ Younger mothers may be less prone to postpartum depression due to the use of newer sources of information, having higher education, and pay attention to the importance of prenatal care. Also, the results of this study showed that there is a significant relationship between maternal education and postpartum depression, which is consistent with Rahmani's research findings..$^{23,25}$ In participants who had a university degree, depression was less noticeable. It seems that in educated people due to more awareness about the issue of infertility and the proper treatment of this case and more suitable mechanisms for coping, depression, and anxiety are less than other people. In this study, there was no relationship between the duration of infertility with depression which is contrary to the results of Ramezanzadeh et al in Tehran, they concluded that there was a significant relationship between postpartum depression and duration of infertility, etiology of infertility, the level of education and occupation of women, but anxiety is related only to the duration of infertility and their educational level. ${ }^{26}$ The reason for this difference is the variety of the population due to geographical location, individual life, cultural differences, and the different attitudes to infertility from altered societies. One of the benefits of our study is the assessment of primigravidae from different socio-economic levels. Based on the results, marital dissatisfaction, a predisposing factor for postpartum depression. In a study in Kashan on 204 mothers, three factors, including the quality relationship with spouse and family and history of depression, had a statistically significant relationship to postpartum depression. ${ }^{27}$ In our study, there was a significant relationship between marital satisfaction and postpartum depression, which means that marital satisfaction in a severe depression of infertile women reduced. This result is similar to the study by Wang et al. They stated that the frequency of mental disorders and dissatisfaction with the marital relationship was higher in the case group (infertile women) than in the control group. ${ }^{28}$

\section{Conclusion}

Regarding the results obtained in this study and comparison with existing studies, the infertility problem can cause mental and psychological disorders in women. It seems that marital satisfaction and its relationship with different factors and the proper interventions by health care providers are necessary to prevent postpartum depression in these women. Intervention such as public education, raising awareness of people about different aspects of infertility, helping infertile couples to cope with stress, teaching problem-solving skills, and the decisionmaking process on treatment and resolving marital and family conflicts following treatment of infertility can help couples following treatment of infertility. In order to achieve these goals, it seems that the presence of psychiatrists and clinical psychologists in infertility diagnostic and treatment centers seems necessary.

\section{Conflict of Interest Disclosures}

The authors declare that they have no conflict of interests.

\section{Ethical Statement}

All participants have given explanations of the research, aims as well as assured that the information would be confidential. Before enrolling in the study, each participant required to provide informed consent, through which they indicated that they understood (a) what expected of them and (b) that they were under no obligation to participate in or complete this questionnaire.

\section{Acknowledgments}

This research supported by research and technology deputy of the Hamedan Branch, Islamic Azad University. We thank our colleagues from who provided insight and expertise that greatly assisted the research. We would like to show our gratitude participants for their commitment during this study.

\section{References}

1. Raymo JM, Park H, Xie Y, Yeung WJ. Marriage and family in East Asia: continuity and change. Annu Rev Sociol. 2015;41:471-92. doi: 10.1146/annurev-soc-073014-112428.

2. Jaffe J, Diamond MO. Reproductive Trauma: Psychotherapy with Infertility and Pregnancy Loss Clients. Washington, DC: American Psychological Association; 2011.

3. Multiple gestation associated with infertility therapy: an American Society for Reproductive Medicine Practice Committee opinion. Fertil Steril. 2012;97(4):825-34. doi: 10.1016/j.fertnstert.2011.11.048.

4. Redshaw $M$, van den Akker O. Maternal mental health and wellbeing. J Reprod Infant Psychol. 2007;25(4):253-4. doi: 10.1080/02646830701669497. 
5. Massarotti C, Gentile G, Ferreccio C, Scaruffi P, Remorgida $\mathrm{V}$, Anserini P. Impact of infertility and infertility treatments on quality of life and levels of anxiety and depression in women undergoing in vitro fertilization. Gynecol Endocrinol. 2019;35(6):485-9. doi: 10.1080/09513590.2018.1540575.

6. Masoumi SZ, Khalili A, Shayan A, Yazdi-Ravandi S, Ahmadi $S$, Roushanaei G. The effect of exclusive breast feeding counseling on knowledge and attitudes of mothers with premature infants. Pajouhan Scientific Journal. 2016;15(1):529. doi: 10.21859/psj-15017. [Persian].

7. Peterson BD, Gold L, Feingold T. The experience and influence of infertility: considerations for couple counselors. Fam J. 2007;15(3):251-7. doi: 10.1177/1066480707301365.

8. Tüzer V, Tuncel A, Göka S, Doğan Bulut S, Volkan Yüksel F, Atan A, et al. Marital adjustment and emotional symptoms in infertile couples: gender differences. Turk J Med Sci. 2010;40(2):229-37.

9. Peyvandi S, Hosseini SH, Daneshpour MM, Mohammadpour RA, Qolami N. The prevalence of depression, anxiety and marital satisfaction and related factors in infertile women referred to infertility clinics of Sari city in 2008. Journal of Mazandaran University of Medical Sciences. 2011;20(80):2632. [Persian].

10. Peterson BD, Newton CR, Rosen KH. Examining congruence between partners' perceived infertility-related stress and its relationship to marital adjustment and depression in infertile couples. Fam Process. 2003;42(1):59-70. doi: 10.1111/j.15455300.2003.00059.x.

11. Repokari L, Punamaki RL, Unkila-Kallio L, Vilska S, Poikkeus $P$, Sinkkonen J, et al. Infertility treatment and marital relationships: a 1-year prospective study among successfully treated ART couples and their controls. Hum Reprod. 2007;22(5):1481-91. doi: 10.1093/humrep/dem013.

12. Khademi A, Alleyassin A, Agha-Hosseini M, Ahmadi Abhari A, Esfhandi H, Fakhimi Derakhshan K. Depression and infertility: evaluation of 681 infertile women using Beck depression inventory. Hayat. 2004;10(2):13-21. [Persian].

13. American Psychological Association (APA). Diagnostic and Statistical Manual of Mental Disorders (DSM-5®). Arlington VA: APA; 2013.

14. Allison J. Conceiving silence: infertility as discursive contradiction in Ireland. Med Anthropol Q. 2011;25(1):1-21. doi: 10.1111/j.1548-1387.2010.01123.x.

15. Mclntosh MD, Ferrando S. Perimenopausal postpartum depression after conception by assisted reproductive technology. Psychosomatics. 2010;51(4):345-8. doi: 10.1176/ appi.psy.51.4.345.

16. Cox JL, Holden JM, Sagovsky R. Detection of postnatal depression: development of the 10-item Edinburgh Postnatal Depression Scale. Br J Psychiatry. 1987;150:782-6. doi: 10.1192/bjp.150.6.782.
17. Montazeri A, Torkan B, Omidvari S. The Edinburgh Postnatal Depression Scale (EPDS): translation and validation study of the Iranian version. BMC Psychiatry. 2007;7:11. doi: 10.1186/1471-244x-7-11.

18. Busby DM, Christensen C, Crane DR, Larson JH. A revision of the Dyadic Adjustment Scale for use with distressed and nondistressed couples: construct hierarchy and multidimensional scales. J Marital Fam Ther. 1995;21(3):289308. doi: 10.1111/j.1752-0606.1995.tb00163.x.

19. Matinnia N, Abdul Rahman H, Ibrahim F, Ghaleiha A, Akhtari-Zavare M, Jahangard L, et al. Predictors of fear related to childbirth among Iranian primigravidae. Glob J Health Sci. 2017;9(3):266-75. doi: 10.5539/gjhs.v9n3p266.

20. Hahn-Holbrook J, Cornwell-Hinrichs T, Anaya I. Economic and health predictors of national postpartum depression prevalence: a systematic review, meta-analysis, and metaregression of 291 studies from 56 countries. Front Psychiatry. 2017;8:248. doi: 10.3389/fpsyt.2017.00248.

21. Kiani Z, Simbar M, Dolatian M, Zayeri F. Correlation between social determinants of health and women's empowerment in reproductive decision-making among Iranian women. Glob J Health Sci. 2016;8(9):54913. doi: 10.5539/gjhs.v8n9p312.

22. Falah-Hassani K, Shiri R, Vigod S, Dennis CL. Prevalence of postpartum depression among immigrant women: a systematic review and meta-analysis. J Psychiatr Res. 2015;70:67-82. doi: 10.1016/j.jpsychires.2015.08.010.

23. Rahmani F, Seyedfatemi N, Asadollahi M, Seyedrasooli A. Predisposing Factors of Postpartum Depression. Iran Journal of Nursing. 2011;24(72):78-87. [Persian].

24. Beck CT. Predictors of postpartum depression: an update. Nurs Res. 2001;50(5):275-85. doi: 10.1097/00006199200109000-00004.

25. Lashgaripour K. Postpartum depression and related factors: a 4.5 months study. Journal of Fundamentals of Mental Health. 2011;13(52):404-12. doi: 10.22038/jfmh.2011.928. [Persian].

26. Ramezanzadeh F, Aghssa MM, Abedinia N, Zayeri F, Khanafshar N, Shariat $M$, et al. A survey of relationship between anxiety, depression and duration of infertility. BMC Womens Health. 2004;4(1):9. doi: 10.1186/1472-6874-4-9.

27. Mousavi SGA, Sabahi-Bidgoli M, Omidi A, Kosha Z, Ghavami M, Gorji Z, et al. Prevalence of postpartum depression and its relation to some psychosocial factors in mothers referred to health centers of Kashan during 2007-8. Feyz Journal of Kashan University of Medical Sciences. 2011;15(3):247-53. [Persian].

28. Wang K, Li J, Zhang JX, Zhang L, Yu J, Jiang P. Psychological characteristics and marital quality of infertile women registered for in vitro fertilization-intracytoplasmic sperm injection in China. Fertil Steril. 2007;87(4):792-8. doi: 10.1016/j.fertnstert.2006.07.1534. 